\title{
Reflection on the Dangers of 'cultural racism' in Intercultural Education
}

\section{Zvi Bekerman}

The Hebrew University of Jerusalem, The Seymour Fox School of Education, Melton Center, Israel

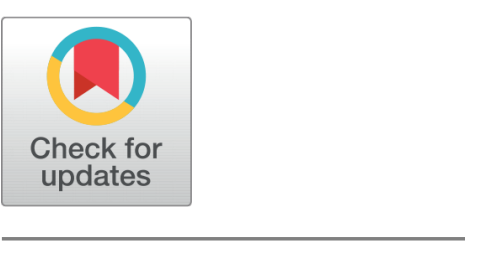

Received 2019-10-30

Revised 2019-11-17

Accepted 2019-12-17

Published 2020-01-15

Corresponding Author

Zvi Bekerman,

mszviman@mscc.huji.ac.il

DOI https://doi.org/10.7821/

naer.2020.1.534

Pages: 1-14

Distributed under

Creative Commons CC BY 4.0

Copyright: (C) The Author(s)

\section{ABSTRACT}

This paper assesses the dangers of the use of the concept 'culture' in present political and educational rhetoric. The first section offers a critique of the use of the term 'culture' in the so-called intercultural educational efforts. It asserts that 'culture' in its present use is a proxy for 'race' and supports views, which ignore diversity and suggest, purposely or not, an homogeneity which can easily spread into the sphere of biological resemblances and differences. The paper, then, identifies possible alternative understandings of culture through the examination of the contribution of anthropology to cultural research. In the last section of the paper suggestions are made to overcome current approaches to intercultural education through a call to diversify the understanding of diversity to include not only ethnic/cultural differences but also, physical, and cognitive ones. To achieve this goal a turn to the ontological and the training of teachers as 'critical experts of design' is suggested.

\section{Keywords INTERCULTURAL EDUCATION, TEACHER TRAINING, CULTURE,} RACE, ONTOLOGICAL TURN

\section{INTRODUCING THE DANGERS OF CULTURAL RHETORIC}

I know little about the algorithm that drives Google Books Ngram Viewer but if to judge by the results I get when registering the words 'culture, race' in the 'Graph these commaseparated phrases' box, I have little choice but to worry about the growing use in education of compound words or expressions which include the word "culture" (e.g. multicultural, intercultural, culturally sensitive, etc.). Whether or not we should trust the results is an important question, not to be dealt with here, and yet in spite of its many problems, the results provided by Google Books Ngram Viewer are striking. They show that around the 1940 's with the decrease in the frequency of the use of the word 'race' (which had been steadily growing until then), the word 'culture' seems to move in the exact reverse direction. Could this mean that 'culture' is the new term for 'race'?

Clearly, we are not the first to question the use of culture in political/educational rhetoric. Cultural approaches as opposed to racial ones have been shown to perpetuate hidden and devious forms of exclusion and inequality (Powell, 2000). Moreover, we are not the first to 
denounce the potential similarities among concepts such as race, ethnicity or culture, all of which seem to unduly neglect diversity; and more importantly, in-group diversity (Heinz, Müller, Krach, Cabanis, \& Kluge, 2014).

And yet, culture reigns in the rhetoric of educational policy and practice till today. All too often it is used as a proxy for 'race' suggesting that populations of certain area or political entity belong to a definite 'culture' thus ignoring diversity and suggesting purposely or not a homogeneity which can easily spread into the sphere of biological resemblances and differences (Balibar, 2011; Martinez Mateo, Cabanis, Stenmanns, \& Krach, 2013).

Race as an analytical concept has been progressively rejected in the social sciences; for example, the Association of American Physical Anthropologists (AAPA) back in 1996 expressed itself against and published a statement condemning any suggestions that 'race' relates to biology and rejected the concept as lacking any scientific utility (Cartmill, 1998). Culture has not yet been as lucky.

Thus, in present theorizing, 'culture' points at groups of people, often conational, thought to be comparable with regard to patterns of social and individual activity, but also recognized as belonging to a common ethnic and biological group (i.e. genetic conformation and brain function) and also sharing a heritage (i.e. practices and beliefs; see, for example, Chiao, 2010 ; Han et al., 2015 ; Han \& Northoff, 2008).

Present understandings of culture (many, not all) are embedded in the positivistic perspective that has characterized traditional Western scientific views over the last few centuries. Culture in these paradigmatic perspectives is viewed as a kind of matter that is ideal, objective, self-sufficient, static and lacking vibrant and evolving historical contexts which, different from identity, exists outside the self (Bekerman, 1999; Mcdermott, 1993). At times, culture is achieved so independently in the eyes of theoreticians that it is observed as acting on humanity.

It is surprising and noteworthy to check that this monolithic understanding of culture contradicts its etymology. The English word 'culture' is derived from Latin cult and cultura$a e$, meaning 'work', as in agri (Latin for field) -culture (Latin for work) as well as words in various languages referring to Divine worship (work-ship). Culture in this sense is evidently not an object, but an infrastructure for growth, action and perpetual human activity. In short, culture is not a thing in people's minds or in a cage, which delimits people's activity, but a process, more a verb than a noun.

Raymond Williams, in Culture and Society (1961), suggests that near the end of the eighteenth century, five familiar terms acquired a new and important meaning. These terms industry, democracy, class, art and culture- respond to and fashion the social, economic and political modifications that influence our world to this day. Then, the concept 'culture' was conferred a distinctive and abstract meaning, addressing two developments taking place in the emerging national dominant community: on the one hand, it reflected the Christian distinction between moral and rational pursuits and the production of goods and merchandises in a world of industrial expansion: and on the other, it positioned itself as a human court that rises above practical human judgment. These events accord significance to the understanding of culture postulated by the British educator and philosopher 
Matthew Arnold: "The best which has been thought and said in the world," the best we have to learn and teach. It is worth recalling in this context that according to Kant, 'the best', (i.e. good) necessarily lacks purpose (Bourdieu, 1984). This view grants the ruthless distinction between "high" and "low/popular" culture, a difference that prevents, for the most part, the infiltration of unfamiliar (i.e. non-hegemonic) cultural aspects into the pantheon of the dominant culture that the assumed (multi or inter) 'educational culturalism' wishes to change.

As hinted at above, culture and its essentialization are closely related to the development of the nation-state. Elias (1998) described the mutual relations between these two phenomena, a process that comprises the move of culture expressed and acknowledged as fluid and in constant evolution, during the course of interpersonal and group encounters, to its understanding and management as an ordered, well-rounded, locked and static system of cultural objects or matters, such as concepts, ideals, customs, texts and rituals, finished and sovereign in themselves. When conceived as such, culture may be used to nurture unity between inhabitants of a particular nation-state's territory, in so doing nullifying local-regional and linguistic distinctions said to belong, now, to the national group.

The new and radical arrangements represented by the nation-state were in need of an operative apparatus for application, supervision and control that grants its owners active, operative and complete control over the use of violence in society (Giddens, 1991; Smith \& Bond, 1998). The educational system provides the application system. Gellner (1983) perceives the nation-state as a political and socioeconomic phenomenon that develops in a modern Western background and is associated with related processes of industrialization and mass education. By instituting a culture that is simultaneously standardized, anonymous and universally literate, the nation-state aspires to control all populations living within it. All the populations that live in a country, irrespective of their affiliation to the culture of their initial group, are obliged to reinforce and uphold the national culture. The cultural literacy that the state demands of its citizens is determined by the political/cultural elites that founded the state and are interested in perpetuating it.

These elites, however, represent such literacy as though it were not particularistic but rather universal and lofty: only one type of cultural literacy -its own-is considered legitimate and acceptable by each such elite. In short, culture serves both to differentiate among humans and also to homogenize them, and schools are the national conduit for shaping and sustaining a given hegemonic culture.

Considering the above observations, it seems that indeed cultural talk rephrases and remakes the race discourse that predominated following the expansion of philosophy and science in the nineteenth century and at the beginning of the twentieth (Haraway, 1991). The setting of cultural rhetoric may soften racism somewhat, but the result, like that of race talk, allocates people to a static origin from which there is no flight. As such, educational cultural discourses do not provide any innovative solution to inequality but rather offers an alternative space in which tolerance of the cultures of others is suggested as a replacement for equality and even as a justification for its non-existence. Just as race theory explains the 'inferior' economic and social class of 'marginal' groups in society according to their 
racial affiliation, multicultural conceptions explain it according to cultural affiliation. In the latter case, however, these differences are not used as a sword with which to impale these groups but a reason for celebration of human variety, without distinguishing between rich and poor or between strong and weak. Most important of all, it provides an appropriate rationalization for inequality (Malik, 1996; Verenne \& Mcdermott, 1998).

Thus, cultural discourses serve the hegemonic powers by explaining existing gaps and the need to institute some kind of order (replication) to 'rectify' it, while the liberals, for humane reasons, seek to allow every culture its 'natural' development and thereby ensure continuation of inferiority. As Malik (2000) and other authors have claimed (Bhabha, 1990; Gunew, 1990), liberals, too, have forgotten that the cultural authenticity they seek to defend is not a remnant from the ancient past but a creation of none other than the Colonial Era.

When these developments are not accounted for in educational efforts in general and in intercultural/multicultural educational efforts in particular, they risk enhancing that same reality they anticipated to overcome. Education is in urgent need of revising its paradigmatic bases while problematizing the social political structures that maintain the conflicts it tries to overcome.

\section{CULTURE IN EDUCATION}

It is not that we do not believe that in schools and other educational settings or in a variety of life events people do not encounter difficulties adapting to new situations. Indeed immigrants of sorts might find difficulties when attempting to find jobs or friends in an environment in which they do not know the language used or the type of relationship needed to facilitate their adaptation and survival. We can even agree that some students, newcomers into an unknown educational environment might encounter obstacles to learning (the way things are thought in the host society); yet, attaching these difficulties to (only) culture, as it seems is done, for the most part, in the intercultural literature, seems to us to be irresponsible, especially when used to ignore other structural considerations.

The modern perspectives on culture are not to be seen as working in isolation. When considering the two major modern premises, which seem to guide the work of educational institutions toward cultural recognition and sensibility, we realize that two underlying assumptions stand at their basis: the incontestable existence of an inner self; and, the unquestionable existence, or should we say pre-existence, of culture. Accordingly, all involved in the educational struggle for cultural continuity, recognition and/or tolerance believe that culture is a 'thing' carried by a 'self'.

Abandoning these positivistic viewpoints might help re-conceptualize our present condition; not all might be achieved but education should, at least, earnestly contemplate, and ultimately incorporate, understandings suggested by newer developments in the fields of cultural studies, literary criticism, anthropology and cultural psychology, influenced by strong interpretative and pragmatical inclinations. Within these present views, past perspectives of cultures as consistent and distinct meaning structures, common to all members, have been shown not to be mistaken. 
No group possesses primal origins. Whatever elements they may have, if any, are the result of human activity enacted repetitively within their respective historical contexts. Given that culture is a human construction in a given context, the apologetic position taken by liberal powers is not required by what they consider 'authentic' about culture but rather by the partners to the context in which it is produced.

\subsection{The evolution of culture in anthropology}

It thus appears that the theoretical assumptions underlying multiculturalism are not powerful enough to yield the proffered salvation. Moreover, the absence of a critical attitude towards these assumptions may indeed prove harmful. To identify the possible alternatives to this type of cultural awareness, we examine the traditional contribution of anthropology to cultural research.

As early as 1940, Boas (1940) struggled to rid cultural considerations from any attention to race, disagreeing with the prevailing conception of culture as a kind of distinct and single monad. A particular culture and its potential merit cannot be attributed to its associated nation, for cultures are always interconnected in a self-nourishing reciprocal system. Said culture cannot be examined in isolation. Culture cannot be approached in the language of the individual but only in that of the many. No culture can be studied on its own; any approach to an understanding of culture must begin with examination of numerous cultures in a given historical/social fabric that underscores their reciprocal links (Wolf, 1994).

Anthropologists like Mead (1942), who highlighted the prominence of acculturation, pointed at the fact that a newborn can become a member of any group regardless of its biological cultural heritage or the degree of difference between target and source group. Claude Levi-Strauss (1955) went even farther, claiming that all personality types can exist in all cultures, if only because all human beings are capable of rejecting the dictates of the culture into which they were born. People may not have a choice of birthplace or its culture, yet they remain capable in principle of rejecting any cultural element they choose.

Association with a group is not an issue of identity but of identification (Carbaugh, 1996a; Varenne \& Mcdermott, 1998) that progresses along human interaction and is formed and perceived as a kind of cultural activity conducted together with friends and neighbors. In diverse social and historical contexts, a similar behavior may give rise to discrete kinds of group identification. Accordingly, being 'Spanish' or 'French' is not a destiny but an achievement, reached with the help and approval of all those involved in efforts conducted at a given moment in history. Ideas, principles, outlooks and particularly situations in which both supporters and detractors are involved, are active partners in the structuring of identification through complex and energetic situated social activity. 'Spanish' and 'French' are not traits carried by people in their minds but the results of hard societal work conducted and consummated in the contexts in which these characteristics are available; thus 'Spanish' and 'French', if at all characteristics, are in the world.

Intercultural and multicultural perspectives pursue a solution to differences that produce troubles in a modern world in which many cultures are located in a single social sphere. We sustain that such perceived differences are not only difficult to take for granted but also 
mistaken. Modernity has not given rise to multiple cultures but to wide sociocultural variations. Accepting or rejecting one or another cultural shade is not a zero-sum game where the only two possible options are assimilation or marginalization. If there are those who reject this 'truth', they are the ones who may have a strong interest in perpetuating national/nationalistic ideologies focused on the reification of identity and culture so as to preserve the powers of a national hegemony (Hall, 1996; Zizek, 1997), but do not represent history factually. The ruling group's reasoning is obvious: accounting for otherness is preferable to accountability for it.

The developments mentioned consider culture 'as a whirlpool more than as an island' (Bauman, 1999, p. 92). Cultural identities strengthen their unity not by trusting values from the past but by reshaping and offering new understandings of cultural materials available to all. Cultural development is consolidated through translation -an act that from the outset does not address the intercultural sphere alone but also accounts for all communicative activity between human beings, even those who ostensibly belong to the same culture (Becker, 1995; Ortega \& Gasset, 1957). Thus, the arguments propounded in this paper should not be read as a call against pledging allegiance to one community or another -nor against group diversity- but rather against their understanding as having any unique character.

To reach a situation in which culture has no exclusive value needs an urgent revision of the concepts of culture and identity as acknowledged in the West at present, it also requires examining our present epistemological and ontological perspectives $s$ and how these affect the organizations reflected in the nation-state. Modernity has directed our understanding of culture as a type of jail in which the self and its identity are imprisoned and has led us to consider relations and interactions among, so to speak, diverse cultural identities as the expression of a communication problem. The theoretical developments reviewed suggest a possible different interpretation. As culture has been reinterpreted as being soft, porous and dynamic, so too is the cultural self and its identity. Bakhtin (1984) non-coincidence principles concerning humanity expresses this well. Zizek (1997), in turn, underlines that a person's prima facie position as an unfinished entity in continuous dialogue with the surroundings may well constitute a solution to the communication issue and not necessarily the problem. Additionally, the problems encountered have nothing to do with the linguistic constraints that prevent our understanding one or other cultural language. The impossibility of grasping the exact meaning of a given symbol seems to be universal to humanity. Therefore, "enlightenment" is undermined by perspectives which suggest culture, any culture, has clearly delineated boundaries which are in need or merit recognition. Only an understanding of culture that mandates equality to all, because everyone has the right to choose who they want to be, will allow us to realize "enlightenment" and to accord it the appropriate universal meaning to support variation.

Within this framework, rather than positioning culture a priori, culture is positioned in social communicative ways as the actual modelling of interactive processes themselves (Carbaugh, 1996b). Culture is neither 'out' nor 'in,' but in-between - accomplished and erected unceasingly in social concert. Together with the interruption of an appreciation of culture 
as preexistent, congruent and coherent, a new view of self is projected. This self of high modernity or postmodernity (Gergen \& Gergen, 1997) is not any more crucial or necessarily stable or cohesive, but, rather manifold and ephemeral. The 'self' still evolves but it does not become definite; the self' is now contextualized in social interactional events where it becomes in dialogue, taking many shapes and manifestations (Harre \& Gillett, 1994).

These issues -the concepts of self and identity, culture, interculturalism, multiculturalism, and the political organization of the nation-state and its monologism- are intimately connected and should be taken into consideration when analyzing the possible outcomes of intergroup education and the strategies that may improve it.

\subsection{Reframing the multicultural/intercultural in education}

Many of the problems of multicultural/intercultural education result from the "epistemological primacy" of the underlying assumptions of identity and culture -that is, the normative epistemology used to justify the naturalization of identity and culture within nationstates- and the anchoring of these assumptions in educational structures. In line with what has lately come to be known as the 'ontological turn' in philosophy and the social sciences (Escobar, 2007; Kivinen \& Piiroinen, 2004; Paleček \& Risjord, 2013; van Dijk \& Withagen, 2014), we are now going to illustrate the importance of moving from the epistemological to the ontological, while describing and analyzing the consequences of this move for intercultural/multicultural education and how it might be implemented.

Within this context, we suggest two main directions. The first, diversifying our understanding of diversity in education and the second, scrutinizing, through educational work, societal interactional details so as to expose the social practices that make relevant certain differences while hiding others which are usually assumed to be internally performed and natural to individuals (Bekerman \& Zembylas, 2018).

\subsection{Diversifying diversity}

In a global and conflictual world, intercultural/multicultural perspectives in education have been called upon to help soothe many of the problems that afflict western societies given the steady increase of immigration coming mainly from poorer countries in the south. Intercultural/multicultural education seems not to have been able to achieve its aims and we believe this to be partially related to it being interpreted by its potential benefactors (mostly first or second generation immigrants) as preventing their full inclusion into the host society by sustaining their differences and subordinate status.

Parallel to intercultural education, a movement towards inclusion in education has developed. This effort is mostly geared towards the inclusion, in 'regular' educational tracks, of people suffering from a variety of physical and cognitive 'disabilities'; believing their inclusion will not only benefit their own intellectual development and educational achievements but also benefit those who welcome them into their midst (Sailor, 2017; Spaulding \& Pratt, 2015). Last, there are a variety of other inclusion initiatives related to lesbian, gay, bisexual, and transgender (LGBT) sexual orientations and gender identities, also considered traditionally within the realm of debilitating differences, to include these differences 
and have them acknowledged within the regular educational systems (Flores, 2012; Tayler \& Price, 2016).

The three trends described above all depend on the recognition of differences, be these cultural, physical, cognitive and sexual orientation; and all three point at inclusion, recognition, and tolerance as a path to a more sensitive approach to social justice.

We believe it to be of central importance to widen our present perspective on intercultural/multicultural education by including all other mentioned differences within its scope. This would primarily relax the emphasis on cultural (racial) differences and afford participants the understanding that what the educational project is dealing with is 'difference'; multiple types of differences, all imposed by a, so-called, 'normal' perspective (Bradshaw, 2017).

We all should remember that difference is all there is. No two human beings (some would say not even identical, monozygotic, twins) are totally similar. If so, no two humans are ever identical and differences between them can be found. The fact is that most of us, in our context of birth and belonging, fail to appreciate many differences which, as stated, factually exist - that is to say they are measurable. Differences are everywhere and we are also taught which differences we should pay attention to.

In a sense we are calling for the diversification of diversity. For a more inclusive approach to differences, which emphasizes that the existing ones (ethnic/cultural, physical, cognitive, etc.) all have in common that they frame certain differences (and not others) for us to pay attention to.

\subsection{Critical Experts of Design}

Developing educational strategies to improve so called intercultural/multicultural conflicts entails that we first help participants become 'critical experts of design' (Bekerman, 2009; Bekerman, Zembylas, \& Mcglynn, 2009) so they can problematize the relationship between the reified concept of identity/culture and the political organization of the nation-state.

Scrutinizing societal interactional details can reveal that nationalism, racism, and patriotism do not commence in people's minds but are instituted there through popular culture, social habits, rituals and ceremonies, at a substantial cost. Though challenging and complex, educational work, exposing the activities that are typically presumed to be internally performed by and natural to individuals, is the only route by which we can identify those strategies against which our struggle should be directed.

Any solution requires a radical change in educators' perspectives. Educators must shift their focus from the student's individual mind to focusing on the collaborative strategies through which identity and culture are made apparent, according to standards that are 'impartial', but not falling on the positivist underpinnings of objectivism. To achieve this, we should ask ourselves: Who are exploited and who holds the power in the context we participate in? Which categories are being used, who uses them, who defines them and how and when are they applied?

This questioning is coherent with the cultural analysis approach suggested by Varenne and Mcdermott (1998). They propose that we learn to read the world through detailed 
observation and careful recording of practical activity, always staying open to identifying new criteria through which to name categories/events and their phenomena. This approach lets us change from using the individual or the socializing group as the analytic unit to using the devices by which cultural contexts are shaped and negotiated through social interaction. If properly implemented, such a process will inform policy matters that are no longer connected to culture and its workings but to the analysis of specific identities/cultures and how they are formed in the actual context of present-day societies. When implying that identity and/or culture are not inevitably the right criteria through which to describe reality, cultural analysis suggests that while identity and culture may be legitimate constructs (however hegemonic), they need not result in individual suffering.

To implement this new approach, we need to offer students a variety of literacies with which to appraise the world. Literacies, abundant in theory and rich in descriptive powers so as to be able to cope with the complexities of the contexts and social activities the students will encounter (Hames-Garcia, 2000). Students need expertise in economic discourses to be able to appreciate and discuss commodities. They also need knowledge of esthetic discourses to discuss designs and displays. Understanding of political discourses will afford them the opportunity to discuss policies, and power; and historical discourses will allow them to talk about transformation in organizations, and changing communal trajectories. They also need interpretative discourses to articulate possible and various understandings of the texts and the intertextuality available in multiple settings, which, in concert, create culture. Familiarity with these discourses is necessary for a profound understanding of the hegemonic systems that currently are in control. If we have critiques of the system, we should not view them as mistakes, for example, of curriculum designers or any others involved in policy implementation or design. A proper analysis will uncover that what we usually translate as mistakes are 'achievements' of a system that wishes to maintain conflict in order to sustain the power of the nation-state.

Consequently, the better our instruments of analysis, the richer our understanding of all aspects of the system and the more we discern about possibilities for change. As we move from cognitive psychologized viewpoints of education toward the material specifics of conflict, from the epistemological to the ontological, the possibilities for change grow.

Only as an example, let us consider what it takes to erase the difference made by a wheel chair. Erasing this difference takes, among other things, to create accessible-to-all physical settings. What we are calling for is to ask similar questions for all other differences noted in inclusive projects. We believe much can be gained by asking, for instance, what type of structural (or linguistic) reshaping would take to erase for example a 'transgenderial' or a 'so-called-cultural' difference. The turn to ontology would facilitate much this approach.

A student should not be labeled with ethnic, national or racial labels, not even with cultural, more benevolent, ones. There might be students who were born in Morocco or Luxembourg, but there are no 'Moroccans' or 'Luxembourgers.'

Attention must be directed towards the interactional contexts and their historical trajectories in which categories like, for example, 'Spanish' and 'French' are produced. We should be aware of the practices through which teachers/curriculum/society ask questions, 
give feedback and speak the "precise language" so as to decide on the criteria through which to identify 'French' and 'Spanish' students. The efforts invested by our schools in nationbuilding, the rhetoric of individuality in our mass media, and the inadequate allocation of resources in our society have to be recognized, described, and presented to all participants as tools through which desired changes can be made.

These activities imply a return to children's perspectives that do not depend on pregiven categories to organize and manage the social world. Children appear able to organize subcultures that are free to develop with no high disciplinary cost. They invent their own categories, which change according to contexts they inhabit and their changing needs. Adults at times rejoice in children's normative mistakes, at least in areas they believe "time will take care of," such as language use. However, national western psychologized perspectives turn children towards adulthood like novices avidly learning to become "old." Research has revealed the convincing subcultures children organize (Harris, 1998; Hirschfeld, 2002); adults need to consider that supporting these cultures might afford the possibility of overcoming society's greatest ailments.

In short, critical pedagogy can take the following steps to achieve a new orientation in the contexts we have discussed. First, teachers and students as 'critical experts of design' need to base programs for developing community relations around an exploration of the becoming/shaping? of identity and culture in real life. Second, they need to contest the notion that identity categories (e.g. gender, ethnicity, etc.) are proper categories for describing the world. Third, they must cultivate the expertise of cultural analysis rather than amassing "knowledge" of the characteristics of the "other" and their culture. In short, they should not start with the "other" and its culture as a given but with the collaborative processes through which those others and their cultures are created so as to realize the work it takes to create them; in such a way that, if they so wish, they can dismantle them in the future. Hopefully, efforts will be redirected from a focus on the "other" to collaborative efforts toward making a better world (Bekerman, 2007).

\section{CLOSING REMARKS}

As many other things in our complex world, intercultural or multicultural education is not necessarily bad nor good. What is unfortunate is that, for the most part, when not being careful with the categories they adopt and guide their work they are blinded to the categories' potential slippery outcomes. Culture is such a category and its compounds (intercultural, multicultural), as we have hopefully shown in the above, are no less problematic.

Sure, there is cultural diversity. The work (from Latin cultura-ae) of humans varies according to circumstances and contexts. Moreover, it is true that humans need cultures (this time as in agri-culture, Latin for environments/fields of growth) to live in, as no human lives in isolation. However, deducing from these facts that humans need a particular culture to stick to through life is disregarding the phenomenal adaptability of that which is alive, in our case, that which is human. True, with the passing of time 'cultural' patterns are established, but this does not mean that 'culture' is a monad. As suggested by Barry (2002), 
'culture' does preserve traditional ways because there are not always available reasons to change the way we do things or because doing them cyclically they offer an economical path to organizing communal life. Yet, this does not make them become 'natural' (from Latin nasci for born).

Even more dangerous is the fact that present 'cultural diversity discourses' license and naturalize the exclusion of marginalized subaltern groups under the pretext of offering recognition to their 'natural cultural' baggage, when what these groups need is not a defense of their difference, but a strong call for action to allow for their undeniable equalit (Malik, 2000) .

Intercultural and multicultural education needs to return to the Greco-Roman political ideal; that which drives different 'natural' groups to find common grounds in the 'artificial' (from Latin artificium for handicraft) polis (the public/political sphere). The political sphere is the one where humans work (culture) to free all from their assumed (cultural) nature (Malik, 2005). What is more, the political sphere, when properly implemented, does not negate differences but makes them become available to enrich our horizons, opportunities and possibilities by introducing them into the public dialogue where we deliberate to reach a shared sense of citizenship supported on the basic understanding of human equality.

\section{ADDITIONAL INFORMATION AND DECLARATIONS}

The present paper, while including new materials, is based on two previous papers. Bekerman, Z. (2018). Interfaith education in Muslim, Jewish, Christian schools in Israel. Journal of Religious Education, 66(2), 99-110 and Bekerman, Z. (2009) Identity versus peace: Identity wins. Harvard Educational Review 79 (1), 74-83.

\section{REFERENCES}

Bakhtin, M. M. (1984). Problems of Dostoevsky's poetics (C. Emerson, Ed.). Minneapolis; London: University of Minnesota Press. https://doi.org/10.5749/j.ctt22727z1

Balibar, E. (2011). The genealogical scheme: Race or culture. An Interdisciplinary Journal in the Humanities and Social Sciences, 1, 1-9. Trans-Scripts.

Barry, B. (2002). ulture and equality: An egalitarian critique of multiculturalism (and others, Ed.). Cambridge, Mass: Harvard University Press.

Bauman, Z. (1999). Culture as praxis. London: Sage.

Becker, A. L. (1995). Beyond Translation Essays toward a Modern Philology (and others, Ed.). Ann Arbor: The University of Michigan Press. https://doi.org/10.3998/mpub.13805

Bekerman, Z. (1999). Constructivist Perspectives on Language, Identity and Culture: Implications for Jewish Identity and the Education of Jews (D. Zizenwine \& D. Schers, Eds.). Tel Aviv: Tel Aviv University.

Bekerman, Z. (2007). Rethinking intergroup encounters: Rescuing praxis from theory. Peace Education, 4, 29-41. https://doi.org/10.1080/17400200601171198

Bekerman, Z. (2009). Identity vs. Peace: Identity wins. Harvard Educational Review, 79(1), 74-83. https://doi.org/10.17763/haer.79.1.m30672027u72x63

Bekerman, Z. (2018). Interfaith education in Muslim, Jewish, Christian schools in Israel. Journal of 
Religious Education volume, 66, 99-110. https://doi.org/10.1007/s40839-018-0061-0

Bekerman, Z., \& Zembylas, M. (2018). Psychologized Language in Education: Denaturalizing a Regime of Truth. New York, NY: Palgrave Macmillan. https://doi.org/10.1057/978-1-137 $-54937-2$

Bekerman, Z., Zembylas, M., \& Mcglynn, C. (2009). Working towards the De-Essentialization of Identity Categories in Conflict and Post-Conflict Societies: Israel, Cyprus, and Northern Ireland. Comparative Education Review, 53(2), 213-234. https://doi.org/10.1086/597482

Bhabha, H. K. (1990). DissemiNation: time, narrative, and the margins of the modern nation. In H. K. Bhabha (Ed.), Nation and narration. London: Routledge.

Boas, F. (1940). Race, language, and culture. New York: Free Press.

Bourdieu, P. (1984). Distinction: A social critique of the judgement of taste (R. Nice, Trans.). Massachusetts: Harvard University Press.

Bradshaw, A. C. (2017). Critical pedagogy and educational technology Culture, learning, and technology. In A. D. Benson, R. Joseph, \& J. L. Moore (Eds.), Culture, Learning, and Technology Research and Practice (pp. 8-27). Routledge. https://doi.org/10.4324/9781315681689-2

Carbaugh, D. (1996a). The Playful Self: Being a Fan at College Basketball Games. In D. P. Cushman \& T. J. Smith (Eds.), Situating Selves: The Communication of Social Identities in American Scenes (pp. 39-60). New York: SUNY.

Carbaugh, D. (1996b). Situating selves: The communication of social identities in American scenes. Albany: SUNY Press. https://doi.org/10.2307/358411

Cartmill, M. (1998). The status of the race concept in physical anthropology. American Anthropologist, 100(3), 651-660. https://doi.org/10.1525/aa.1998.100.3.651

Chiao, J. Y. (2010). At the frontier of cultural neuroscience: Introduction to the special issue. Social Cognitive and Affective Neuroscience, 5(2-3), 109-110. https://doi.org/10.1093/scan/nsq064

Elias, N. (1998). Civilization, culture, identity: "'Civilization" and "Culture": Nationalism and Nation State Formation': an extract from the Germans. In J. Rundell \& S. Mennell (Eds.), Classical Readings in Culture and Civilization (pp. 225-240). New York: Routledge. https:/doi.org/ 10.4324/9781351227025-16

Escobar, A. (2007). The 'ontological turn' in social theory. A commentary on 'Human geography without scale. Transactions of the Institute of British Geographers, 32(1), 106-111. https:// doi.org/10.1111/j.1475-5661.2007.00243.x

Flores, G. (2012). Toward a more inclusive multicultural education: Methods for including LGBT themes in K-12 classrooms. American Journal of Sexuality Education, 7(3), 187-197. https:// doi.org/10.1080/15546128.2012.707072

Gellner, E. (1983). Nations and nationalism. Oxford: Basic Blackwell.

Gergen, K. J., \& Gergen, M. M. (1997). The Idea of Narrative in Human Science. In P. Hinchman \& S. K. Hinchman (Eds.), Memory, Identity, Community: The Idea of Narrative in the Human Sciences. New York: SUNY Press.

Giddens, A. (1991). Modernity and self identity. Stanford CA: Stanford University Press.

Gunew, S. (1990). Feminist knowledge, critique and construct. New York: Routledge.

Hall, S. (1996). Introduction: Who needs 'Identity'? In S. Hall \& P. du Gay (Eds.), Questions of Cultural Identity (pp. 1-18). London: Sage. https://doi.org/10.4135/9781446221907.n1

Hames-Garcia, M. R. (2000). Who are our people? Challenges for a theory of social identity. In P. M. L. Moya \& M. R. Hames-Garcia (Eds.), Reclaiming identity (pp. 102-132). Berkeley: University of California Press.

Han, C., Ayala, G., Paul, J. P., Boylan, R., Gregorich, S. E., \& Choi, K. H. (2015). Stress and coping with racism and their role in sexual risk for HIV among African American, Asian/Pacific Islander, and Latino men who have sex with men. Archives of sexual behavior, 44(2), 411-420. 
https://doi.org/10.1007/s10508-014-0331-

Han, S., \& Northoff, G. (2008). Culture-sensitive neural substrates of human cognition: A transcultural neuroimaging approach. Nature Reviews Neuroscience, 9(8), 646-646. https://doi.org/ $10.1038 / \operatorname{nrn} 2456$

Haraway, D. J. (1991). Simians, Cyborgs, and Women: The Reinvention of Nature. New York: Routledge.

Harre, R., \& Gillett, G. (1994). The discursive mind. London: Sage.

Harris, J. R. (1998). The nurture assumption: Why children turn out the way they do. New York: Free Press.

Heinz, A., Müller, D. J., Krach, S., Cabanis, M., \& Kluge, U. P. (2014). The uncanny return of the race concept. Frontiers in Human Neuroscience, 8(836). https://doi.org/10.3389/fnhum.2014 .00836

Hirschfeld, L. A. (2002). Why don't anthropologists like children? American Anthropolgist, 104(2), 611-627.

Kivinen, O., \& Piiroinen, T. (2004). The relevance of ontological commitments in social sciences: Realist and pragmatist viewpoints. Journal for the Theory of Social Behaviour, 34(3), 231-248. https://doi.org/10.1111/j.0021-8308.2004.00246.x

Levi-Strauss, C. (1955). Tristes tropiques (J. Russell, Trans.) (and others, Ed.). Atheneum. NewYork

Malik, K. (1996). The meaning of race: Race, history and culture in Western society (and others, Ed.). Houndmills: Macmillan. https://doi.org/10.1080/00313220500347808

Malik, K. (2000). Universalism and difference in discourses of race. Review of International Studies, 26(05), 155-177. https://doi.org/10.1017/S0260210500001558

Malik, K. (2005). Making a difference: culture, race and social policy. Patterns of Prejudice, 39(4), 361-378. https://doi.org/10.1080/00313220500347808

Martinez Mateo, M., Cabanis, M., Stenmanns, J., \& Krach, S. (2013). Essentializing the binary self: individualism and collectivism in cultural neuroscience. Frontiers in Human Neuroscience, 7. https://doi.org/10.3389/fnhum.2013.00289

Mcdermott, R. (1993). The adquisition of a child by a learning disability. In S. Chaiklin \& J. Lave (Eds.), Understanding practice (pp. 269-306). Cambridge: Cambridge University Press.

Mead, M. (1942). And keep your powder dry: An anthropologist looks at America. New York: W. Morrow.

Ortega, J., \& Gasset, Y. (1957). What People Say: Toward a New Linguistics (W. R. Trask, Trans.). New York: W.W. Norton and Co.

Paleček, M., \& Risjord, M. (2013). Relativism and the ontological turn within anthropology. Philosophy of the Social Sciences, 43(1), 3-23. https://doi.org/10.1177/0048393112463335

Powell, R. (2000). Overcoming cultural racism: The promise of multicultural education. Multicultural Perspectives, 2(3), 8-14. https://doi.org/10.1207/S15327892MCP0203_03

Sailor, W. (2017). Equity as a basis for inclusive educational systems change. Australasian Journal of Special Education, 41(1), 1-17. https://doi.org/10.1017/jse.2016.12

Smith, P. B., \& Bond, M. H. (1998). Social psychology across cultures. London: Harvester Wheatsheaf. Spaulding, L. S., \& Pratt, S. M. (2015). A review and analysis of the history of special education and disability advocacy in the United States. American Educational History Journal, 42(1), 91-91.

Tayler, K., \& Price, D. (2016). Gender diversity and inclusion in early years education. Routledge. https://doi.org/10.4324/9781315718903

van Dijk, L., \& Withagen, R. (2014). The horizontal worldview: A Wittgensteinian attitude towards scientific psychology. Theory \& Psychology, 24(1), 3-18. https://doi.org/10.1177/ 0959354313517415

Varenne, H., \& Mcdermott, R. (1998). Successful Failure: The Schools America Builds. Colorado: 
Westview Press.

Verenne, H., \& Mcdermott, R. (1998). Successful failure: The schools America builds. USA: Westview Press.

Wolf, E. R. (1994). Perilous Ideas: Race, culture, people. Current Anthropology, 35(1), 5-12.

Zizek, S. (1997). The abyss of freedom/ Ages of the world (The Body, in Theory - Histories of Cultural Materialism) (J. Norman, Trans.). Ann Arbor: Michigan University Press. https:// doi.org/10.3998/mpub.11193 